\title{
Erratum to: Prolonged survival in patients with breast cancer and a history of brain metastases: results of a preplanned subgroup analysis from the randomized phase III BEACON trial
}

\author{
Javier Cortés ${ }^{1} \cdot$ Hope S. Rugo ${ }^{2} \cdot$ Ahmad Awada $^{3} \cdot$ Chris Twelves $^{4}$. \\ Edith A. Perez ${ }^{5}$ - Seock-Ah Im ${ }^{6}$ - Patricia Gómez-Pardo ${ }^{7}$ - Lee S. Schwartzberg ${ }^{8}$. \\ Veronique Diéras ${ }^{9}$ Denise A. Yardley ${ }^{10}$ - David A. Potter ${ }^{11} \cdot$ Audrey Mailliez $^{12}$. \\ Alvaro Moreno-Aspitia ${ }^{1} \cdot$ Jin-Seok Ahn $^{13}$. Carol Zhao ${ }^{14} \cdot$ Ute Hoch $^{14}$. \\ Mary Tagliaferri ${ }^{14} \cdot$ Alison L. Hannah ${ }^{15}$. Joyce O'Shaughnessy ${ }^{16}$
}

Published online: 7 September 2017

(C) Springer Science+Business Media, LLC 2017

\section{Erratum to: Breast Cancer Res Treat (2017) \\ 165(2):329-341 \\ DOI 10.1007/s10549-017-4304-7}

The text in panel B of Fig. 1 (progression-free survival for patients with stable, treated brain metastases) was incorrectly labeled as mOS instead of mPFS. All other values and labels are correct. The corrected Figure 1 is given in this erratum.

The online version of the original article can be found under doi:10.1007/s10549-017-4304-7.

Joyce O'Shaughnessy

joyce.oshaughnessy@usoncology.com

1 Ramon y Cajal University Hospital, Madrid, Spain and Vall d'Hebron Institute of Oncology, Barcelona, Spain

2 University of California, San Francisco, CA, USA

3 Medical Oncology Clinic, Jules Bordet Institute, Brussels, Belgium

4 Leeds Institute of Cancer and Pathology and St James's University Hospital, Leeds, UK

5 Mayo Clinic, Jacksonville, FL, USA

6 Seoul National University Hospital, Cancer Research Institute, Seoul National University College of Medicine, Seoul, Korea

7 Vall d'Hebron Institute of Oncology, Barcelona, Spain

8 The West Clinic, Memphis, TN, USA
Institut Curie, Paris, France

10 Sarah Cannon Research Institute, Nashville, TN, USA

11 Department of Medicine, Masonic Cancer Center, University of Minnesota, Minneapolis, MN, USA

12 Centre Oscar Lambret, Lille, France

13 Department of Medicine, Samsung Medical Center, Sungkyunkwan University School of Medicine, Seoul, Korea

14 Nektar Therapeutics, San Francisco, CA, USA

15 Consultant, Sebastopol, CA, USA

16 Texas Oncology-Baylor Charles A. Sammons Cancer Center/ U.S. Oncology, 3410 Worth Street, Suite 400, Dallas, TX 75246, USA 
Fig. 1 Kaplan-Meier estimates for a overall survival and b progression-free survival for patients with stable, treated brain metastases; and c overall survival for patients with radiologically detectable, but stable, brain lesions at study entry. $C I$ confidence interval, $H R$ hazard ratio, $m O S$ median overall survival, $m P F S$ median progression-free survival, TPC treatment of physician's choice
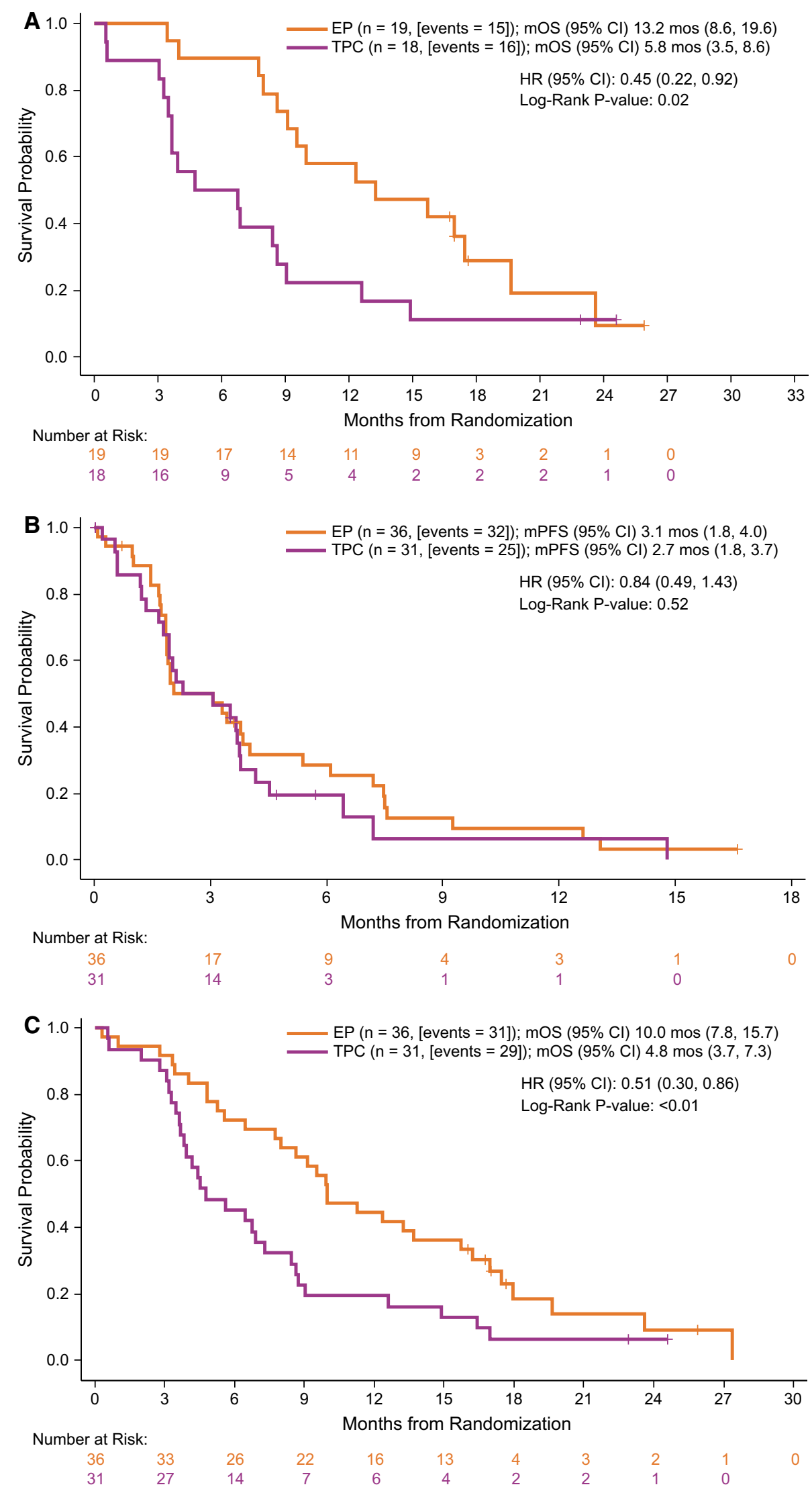